\title{
Protection against neonatal enteric colibacillosis employing E. Coli-derived outer membrane vesicles in formulation and without vitamin D3
}

\author{
Babak Beikzadeh and Gholamreza Nikbakht Brujeni
}

\begin{abstract}
Objective: Enterotoxigenic Escherichia Coli (ETEC) is the cause of diarrhea and even death in humans and offspring of animals. Outer membrane vesicles (OMVs) of the ETEC was prepared and its potential as a vaccine candidate against enteric colibacillosis in neonatal mice was evaluated. Dam mice intradermally injected with ETEC-derived OMVs and OMVs plus an active form of vitamin D3 (avD3). Mucosal and systemic immune responses in mice and passive immunity protection against ETEC lethality in their offspring was investigated.

Results: Immunization of adult mice via ETEC-derived OMV alone and in formulation with avD3 protect offspring from ETEC-induced lethality. Nevertheless, avD3 did not indicate a positive effect on mucosal and systemic immune responses. Only the combination of OMV plus avD3 elicited a significant $(P<0.05)$ increase in the level of specific $\lg A$ antibodies in serum.
\end{abstract}

Keywords: Enterotoxigenic Escherichia coli, Outer membrane vesicles, Vitamin D3

\section{Introduction}

Outer membrane vesicles (OMVs) are a non-living bacterial part that has been used as vaccine candidates [1]. They are secreted from the cell surface and possess proteins, lipopolysaccharides, phospholipids, periplasmic components, DNA and RNA. Using OMVs for immunization purposes have some advantages over common vaccines such as cost-benefit and availability, having partially or whole the virulence factors, and do not require an adjuvant [2-5].

Enterotoxigenic E. coli (ETEC) is an important cause of lethal diarrhea in neonatal calves (Colibacillosis), piglets and sometimes in humans [6-11]. Active immunization of neonates against disease is not practicable and passive immunity is necessary to protect during the first days of life [12]. Despite the massive works done on vaccine

\footnotetext{
*Correspondence: nikbakht@ut.ac.ir

Department of Microbiology and Immunology, Faculty of Veterinary

Medicine, University of Tehran, Azadi Avenue, Tehran, Iran
}

inoculation design to prevent the infection in mothers and offspring's, no broadly protective vaccine is now available, especially for newborn animals [13-15]. Studies on ETEC-derived OMVs have shown that immunization with these particles leads to produce antibodies against bacteria [11, 15-18]. These results demonstrate the active immune responses against OMVs, but they do not show, if the neonate is infected after $24 \mathrm{~h}$ of birth, whether the maternal derived antibodies could protect them from bacteria-induced lethality.

Although there are several whole germ-attenuated, killed or recombinant vaccines to prevent the disease $[14,19-21]$, the bacteria may still lead to the infection of neonates in the early hours after birth [22,23]. As OMVs stimulates the systemic immune response and avD3 can stimulates the mucosal immunity [24-26], we hypothesized that applying avD3 along with OMVs can switch systemic immune responses to mucosal response and robust mucosal immunity and finally increase protection against ETEC in neonatal mice. 


\section{Main text}

\section{Materials and methods}

\section{OMV isolation and characterization}

Bovine ETEC O101: K99 (field strain) were cultured in Luria-Bertani (LB) broth (Merck, Germany) with aeration or, if necessary, LB broth agar plate at $37^{\circ} \mathrm{C}$. Isolation of OMVs was performed as described previously [27]. Bacterial culture was pelleted at $10,000 \times g$ for $15 \mathrm{~min}$ and then the supernatant was transferred to Tangential Flow Filtration system (TFF) (Millipore, DUOBLOC TM, USA) to concentrate high molecular weight proteins and remove low molecular weight proteins (10,000-molecularweight-cutoff). OMVs were prepared with extra filtration through 0.45 and $0.22 \mu \mathrm{m}$ filters. Finally, the supernatant was pelleted using a high-speed centrifuge (Refrigerated SIGMA 3-16K Centrifuge) at 20,000 $\times g$ for $3 \mathrm{~h}$ at $4{ }^{\circ} \mathrm{C}$. Isolated OMVs were aliquoted in PBS and sorted at $-80^{\circ} \mathrm{C}$.

Transmission electron microscopy [11] was used to verify OMV morphology based on Park et al. with some modifications [18]. Vesicles were resuspended in $0.01 \mathrm{M}$ PBS and then passed through a nickel grade 400 mesh. Next10 $\mu \mathrm{l}$ of OMV sample was placed on coated grade with the carbon-reinforced formvar film. After $30 \mathrm{~min}$ at room temperature, the grade was washed with $0.01 \mathrm{M}$ PBS solution (0.5 M BSA and \%0.1 gelatin). The grid was fixed with $0.01 \mathrm{M}$ PBS containing $1 \%$ glutaraldehyde at $4{ }^{\circ} \mathrm{C}$ for $1 \mathrm{~h}$ and then washed again with $0.01 \mathrm{M}$ PBS. Finally, the grid was stained with $2 \%$ phosphotungstic acid (negative staining). Finally, images were obtained using microscope software ZEN lite from ZEISS EM900 transmission electron microscopy.

\section{Immunization regime and challenge protocol}

The source of animals and experiment procedures were approved and monitored by animal care center, Faculty of Veterinary Medicine, University of Tehran. The study population consists of 30 female mice (BALB/c background, 6 weeks old) divided into three groups, containing 10 mice in each group $(n=5$ mice as sham and $\mathrm{n}=5$ mice as immunized). Each two female mice were mated with one age-matched male and immunization was started at day 0, 14 and 28 with OMV alone (two groups) and OMV plus avD3 (one group) via i.d. route following this concentration: for OMV, $100 \mu \mathrm{g}[28,29]$ and for avD3 $(1 \alpha, 25$-Dihydroxycholecalciferol- SigmaD1530), $0.1 \mu \mathrm{g}$ of avD3 in $0.2 \mu \mathrm{l}$ of $95 \%$ of ethanol [19, 25 ] was add to each dose of vaccine. After the pregnancy, the dam mice were separated and monitored until birth. After $24 \mathrm{~h}$ of suckling, all neonatal mice were subjected to oral challenge with $10^{2}$ and $10^{3} \mathrm{CFU}$ of ETEC [30] and returned to their dams to allow a continuous transferring of immunoglobulin from dams to infected offspring. The survival rate of neonatal was recorded for 7 days.

\section{Collection of samples}

Newborn mice at day 7 after challenge and their mothers at week 8 after immunization were euthanized and the blood collected by cardiac puncture. Since all neonates from sham group died in the first $24 \mathrm{~h}$ after challenge, another unchallenged group were sampled. To obtain intestinal lavage fluids, the intestine samples were washed three times with ice-cold PBS containing protease inhibitors. Samples were centrifuged $2500 \times g$ for $20 \mathrm{~min}$ at $4{ }^{\circ} \mathrm{C}$ and the supernatants were sorted at $-20^{\circ} \mathrm{C}$.

\section{Measurement of antibodies titer against OMV}

Serum and mucosal IgG and IgA titers were determined by an enzyme-link immunosorbent assay (ELISA) as described by Schild et al. [31].

\section{Immunization effect on ETEC removal}

To confirm that recovered bacteria from the intestine were the challenge strain, PCR amplification procedure was performed according to Franck et al. [32].

\section{Identification of immunogenic proteins}

Prepared OMVs and two ETEC strains including field isolated strain, O101:K99, and a reference ETEC strain 510 , along with the recombinant K99 were separated by sodium dodecyl sulfate-polyacrylamide gel electrophoresis (SDS-PAGE) and the specificity of OMV-derived antibodies were tested by western blot analysis as previously described [33].

\section{Statistical analysis}

Survival curves were analyzed using Log-rank (MantelCox) test. Student's t test and the One-way ANOVA (Tukey's multiple comparisons test) were used to assess significant differences between groups. All values were expressed as mean $\pm \mathrm{SEM}$.

\section{Results}

ETEC-derived OMVs immunization and survival rate of neonatal

The OMVs, which were obtained from ETEC, have shown spherical shape in different size (50-100 nm), without cell debris (Fig. 1a). After morphological characterization and determination of protein concentration, mice were immunized by ETEC-derived OMVs in formulation with avD3. All sham-immunized group quickly died at first $24 \mathrm{~h}$ of post-challenge, while $25.49 \%$ of OMV immunized group survived until day 7 (Fig. 1b). In contrast, the survival rate of neonatal mice challenged with a low dose of ETEC $\left(10^{2} \mathrm{CFU}\right)$ was significantly improved to 
91.66\% ( $\mathrm{p}<0.0001)$ (Fig. 1c). The OMV plus avD3 group and sham-immunized group (PBS + avD3) indicated a similar pattern with OMV group. Only $21.3 \%$ of immunized group survived at day 7 ( $\mathrm{p}<0.0001)$ (Fig. 1d, e). As a result of bacterial pathogenesis in the sham-immunized group, ascites (accumulation of fluid in the abdomen) was seen in the neonatal mice (Fig. 1f). Survived neonate from immunized mice did not show any adverse physical symptom. Overall, these results demonstrate that immunization of adult mice against ETEC via ETEC-derived OMV protects offspring from ETEC-induced lethality, even in formulation with avD3.

\section{Systemic versus mucosal antibody response}

Sera from immunized group- mother mice (MM) with OMV as well as OMV plus avD3 group indicated a significant increase in IgG level compared to sham-immunized mice. Group immunized by solely OMVs produced more IgG titer than other groups. The levels of IgA titer revealed that only the combination of OMV plus avD3 has the potential to produce IgA antibodies in serum. However, in the intestine, there was no significant difference in IgA level between immunized and sham-immunized group.

In concordance with $\mathrm{MM}$ antibodies response, offspring had a similar level of IgG in their serum and IgA in their intestine. To evaluate whether maternal antibodies are transferred to neonate or not, the levels of $\operatorname{IgG}$ and IgA of MM were compared to those of neonatal mice (NM). Interestingly, the results showed that the levels of antibodies in NM are directly correlated with MM (Fig. 2). However, OMVs had the capability to induce a systemic antibody response, while the avD3 had no effect on mucosal response.

\section{ETEC removal from intestine}

ETEC K99 positive bacteria was detected in all neonates from immunized and sham-immunized groups that were challenged with $10^{3} \mathrm{CFU}$. Only the challenged neonates with a $10^{2} \mathrm{CFU}$ were negative.

\section{Specificity of antibody response}

Western blotting analysis showed specific antibodies that react with multiple bands in OMV extract and whole germ bacteria. Our results indicated the presence of immune dominant proteins $(\sim 14, \sim 22$ and $\sim 30 \mathrm{kDa})$ in OMVs and whole germ bacteria. Comparing to the whole germ ETEC O101: $\mathrm{K}^{+}{ }^{+}$and OMVs, no reactivity in the serum of immunized mice was found for purified K99 peptide (Fig. 3).

\section{Discussion}

Although efforts have been performed in the field of protective colibacillosis vaccine $[6,17]$, a broadly effective vaccine has not been produced yet. In this work, the potential of ETEC-derived OMVs plus avD3 in the induction of mucosal immunity and increase protection against ETEC in the neonate was investigated. ETEC vesicles were isolated from concentrated supernatant through several steps of filtration. Isolated OMVs in terms of morphology such as the range size and purity were confirmed with the others reports $[11,15,16,18]$.

To evaluate the immunogenicity of OMVs and the effects of avD3, we choosed the i.d. route for stimulating the Langerhans cells and induction a strong immune response [34-38]. As expected, OMV immunized group has a higher IgG titer in their sera, unlike the IgA level that did not show significant changes, neither in the sera nor in the intestine. Although i.d. route of immunization can induce mucosal immune responses $[19,44-48]$, in the current study lack of stimulating mucosal immunity could be due to the type of immunization [39-43]. In the contrary to increasing the IgA level in serum, this trend was not observed in MM and NM intestines. Considering the results of survival rates and bacterial detection in the small intestine, it can be concluded that avD3 had no significant effect on an immune response induction against ETEC.

Sera from immunized and sham-immunized groups reacted with similar protein bands of ETEC and OMV. It seems that under natural conditions there are some

\footnotetext{
(See figure on next page.)

Fig. 1 a Electron micrograph of ETEC 0101:K99—derived OMVs. To confirm final product purification of ETEC culture supernatant and vesicles morphology, they were negatively stained and visualize by Transmission electron microscopy. Image was obtained by ZEISS EM900. Bar $=100 \mathrm{~nm}$. Survival rates of respective offspring from immunized and sham-immunized mice. To evaluated the effect of OMV-and sham (PBS) immunization regime on neonatal mice protect against ETEC, $\mathbf{b}$ suckling offspring $(n=50-53$, each group) after $24 \mathrm{~h}$ of birth challenged orally with lethal doses of ETEC $\left(10^{3} \mathrm{CFU}\right)$ and survival was monitored every $12 \mathrm{~h}$ for 7 days. c suckling offspring ( $\mathrm{n}=50-53$, each group) after $24 \mathrm{~h}$ of birth challenged orally with lethal doses of ETEC $\left(10^{2}\right.$ CFU) and survival was monitored every $12 \mathrm{~h}$ for 7 days $\mathbf{d}$ Likewise, respective suckling offspring $(n=52-63$, each group) from OMVs plus avD3-and sham (PBS + avD3) immunization mice, after $24 \mathrm{~h}$ of birth challenged orally with $10^{3}$ CFU. All sham-immunized mice died in the first 24 and $48 \mathrm{~h}$ after challenged with $10^{3}$ and $10^{2} \mathrm{CFU}$ of bacteria respectively. e Survival rate comparison between OMV-immunized group and OMV plus avD3-immunized group. No significant difference was observed in survival rate due to use avD3. $\mathbf{f}$ Ascites was seen as post mortem symptom in all neonatal mice that had no ability to resist against disease (black arrow)
} 
a

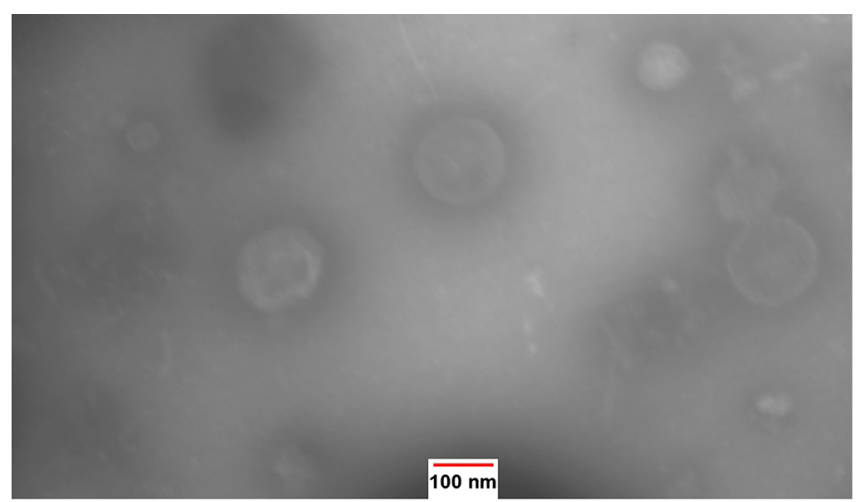

b

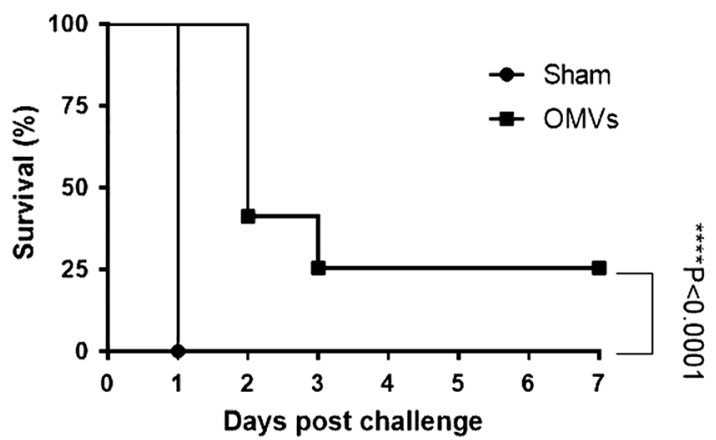

d

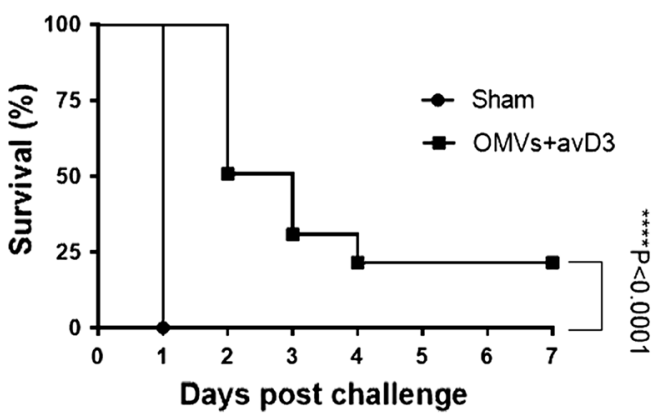

C

$10^{2}$ CFU-ETEC
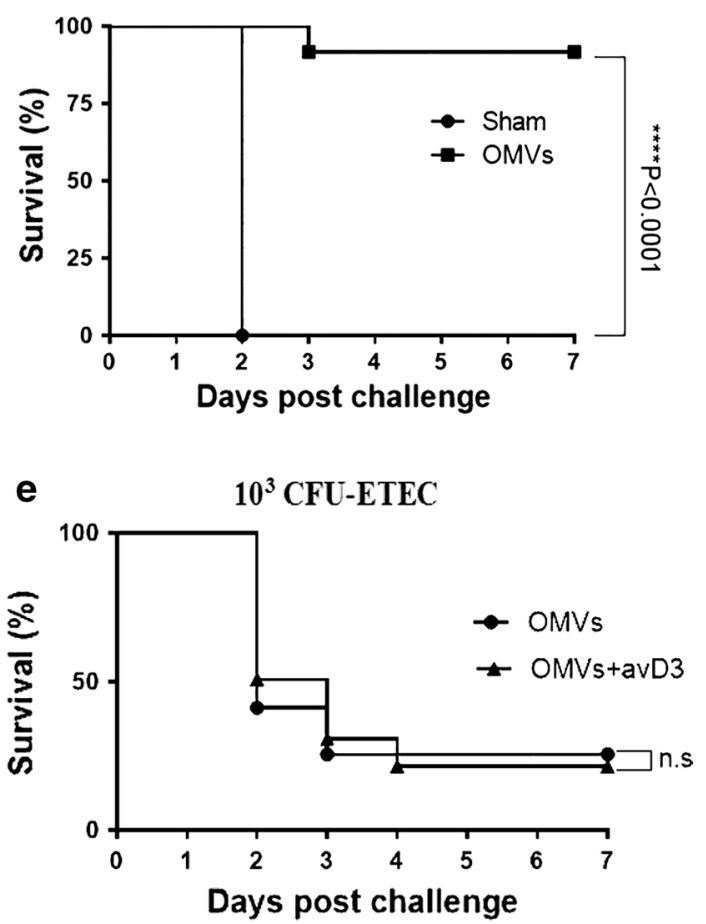

f 

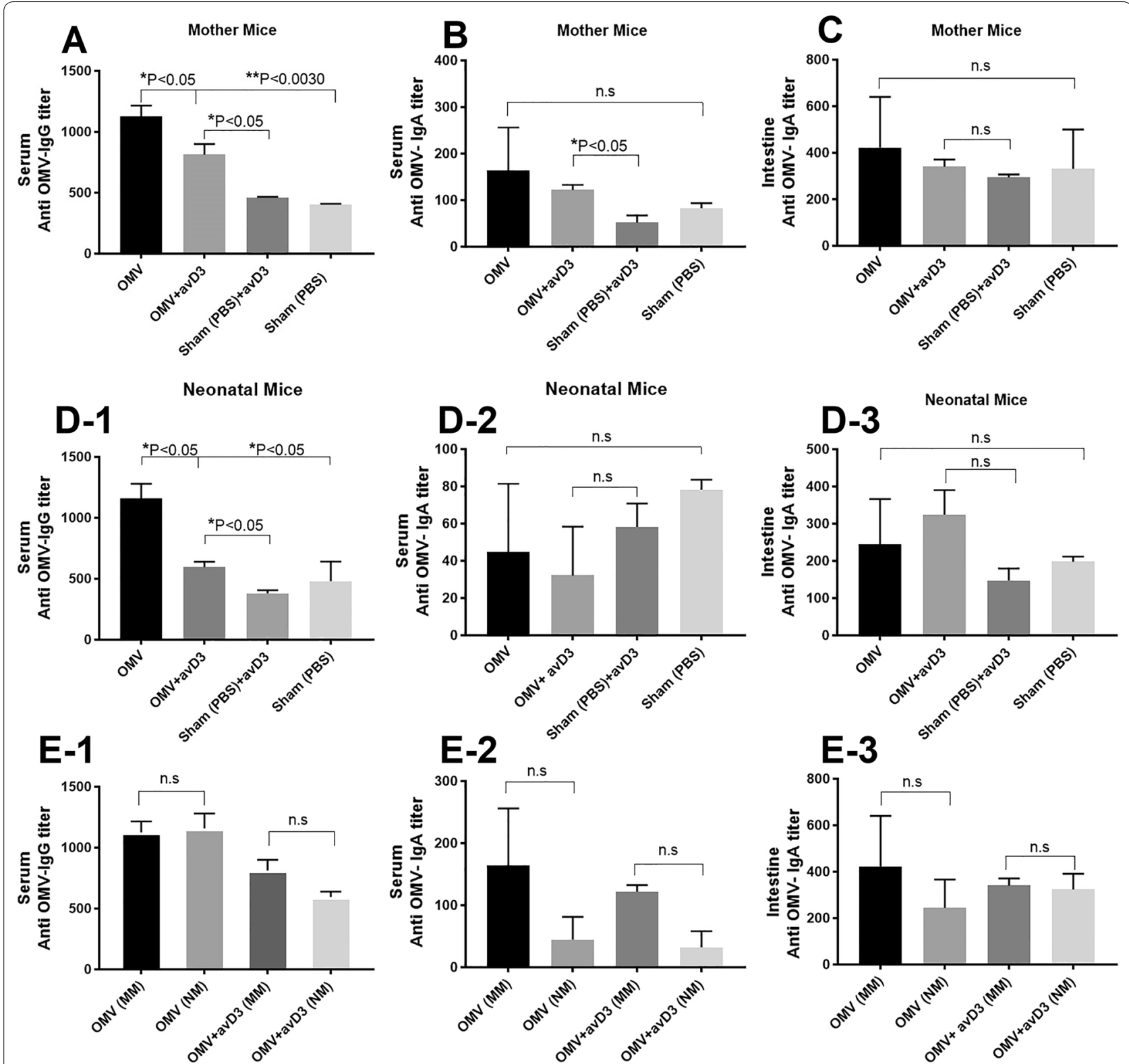

Fig. 2 Serum and intestinal anti OMV- IgG and IgA titers. a-c Mother mice $(n=5$, each group) serum Ig $\mathrm{a}$ and $\lg A$ titers at week 8 after immunization and intestinal IgA titer. (D1-3) Respective offspring ( $n=15-18$, each group) IgG and IgA titers at day 7 after challenge. (E1-3) Comparison of $\lg$ G and $\lg A$ titers in serum and intestine of mother mice and neonatal mice (NM). Comparison of all groups were performed by One-way ANOVA-Tukey's multiple comparison test. Bars represented pooled results (geometric mean \pm SEM)

antibodies against E.coli (as normal gut microbiota), which their levels goes up during immunization. We further analyzed the presence of anti- K99 specific antibodies in immune sera. Fimbria K99 is a highly protective antigen against ETEC infection in cattle and mice [14, 46]. Comparing purified K99 peptide along with ETEC K99+-derived OMVs and whole germ shows that OMVs is not able to induce an antibody response against K99 (Fig. 3). This defect in the immune response is probably due to the removal of fimbria fractions during OMV purification. Nevertheless, our results indicated that anti-K99 antibodies may not be required to induce protective immunity.

Survival rates disclosed a partial protection after challenging with $10^{3} \mathrm{CFU}$ bacteria, while a complete immunity was shown in the challenge with lower dose $\left(10^{2}\right.$ CFU) bacteria. Partial immunity may be due to the incomplete transmission of antibody from mother 


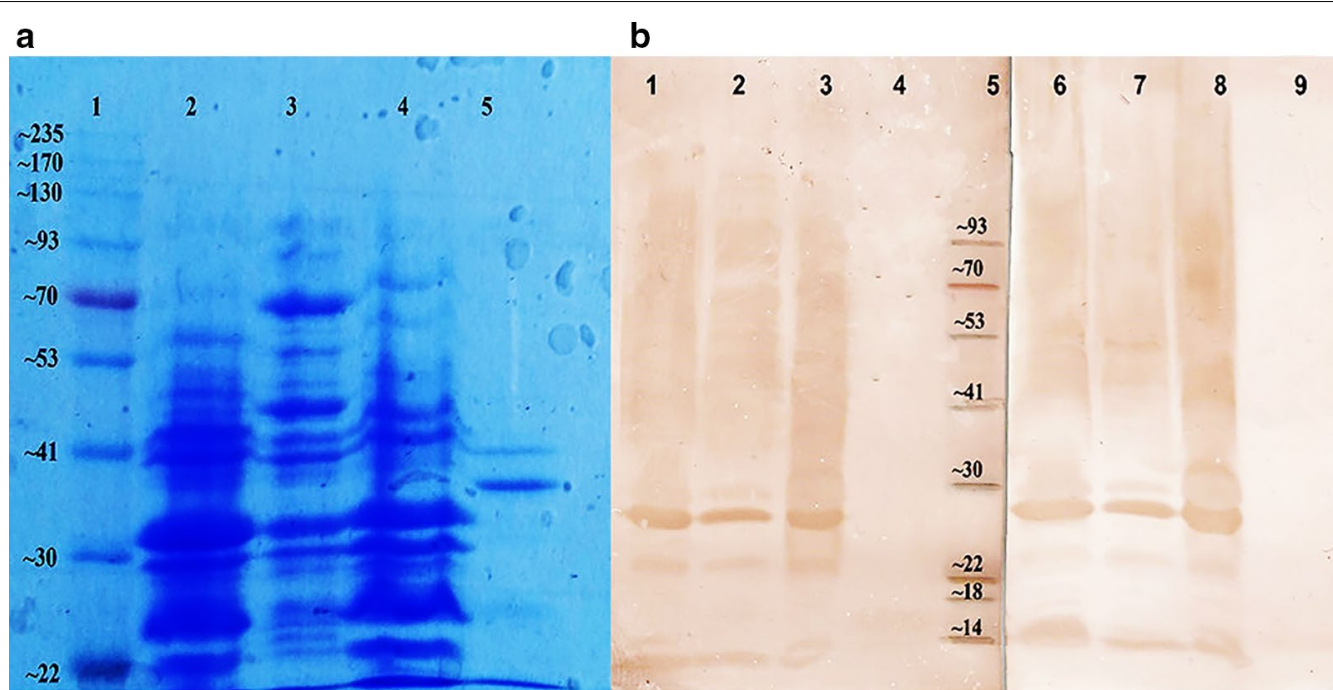

Fig. 3 Specificity of IgG response from immunized and sham-immunized mice. a SDS-PAGE gel: molecular mass of protein standard in kDa (lane 1), ETEC 0101:K99 strain (lane 2), OMVs (lane 3), ETEC 510 (O101:K99) strain (lane 4) and purify K99 protein (lane 5). b Immunoblot of SDS-PAGE gel using immunized sera: ETEC 0101:K99 strain (lane 1), OMVs (lane 2), ETEC 510 (0101:K99) strain (lane 3), purify K99 protein (lane 4), molecular mass of protein standard in kDa (lane 5). Immunoblot of SDS-PAGE gel using sham-immunized sera: ETEC 0101:K99 strain (lane 6), OMVs (lane 7), ETEC 510 (0101:K99) strain (lane 8) and purify K99 protein (lane 9)

to neonates. Since the levels of specific antibodies (IgG and $\operatorname{IgA}$ ) in neonates were similar to dams, it could be speculated that maternal derived antibodies are effective but not adequate for $10^{3} \mathrm{CFU}$ of ETEC. This is noteworthy that under natural conditions, non-immunized animals have low levels of antibody to ETEC and the protection mainly deals with the specificity and adequate level of antibodies. Results of bacterial detection in the small intestine can provide a further evidence for the above statement. However, the distinct specificity of antibodies and their protection level remains to be elucidated.

\section{Conclusions}

In this report ETEC outer membrane vesicles was prepared and tested alone or in formulation with avD3 as a new candidate for colibacillosis vaccine. Immunization of dam mice induced serum and mucosal antibody responses and could elicit protection in neonates. Furthermore, infant mice born to immunized dam had higher survival rates at post challenge by lower dose bacteria. Vitamin D3 did not indicate a positive effect on mucosal and systemic immune responses. Our study may also contribute to the development of those vaccinology methods, which trigger mucosal immunity and result in passive immunity in offspring.

\section{Research limitation}

- Report demonstrated that the use of vitamin D3 along with ETEC-derived OMVs does not increase the IgG and IgA levels production.

- Vitamin D3 had no significant effect on neonatal protection against ETEC lethality.

- Report highlighted that transferring passive immunity to neonate, at sensitive time after the birth, needs more investigation on stimulating the mucosal immunity.

\section{Abbreviations}

ETEC: enterotoxigenic Escherichia coli; OMV: outer membrane vesicles; avD3: active form of vitamin D3; i.d.: intradermal route; MM: mother mice; NM: neonatal mice.

\section{Authors' contributions}

$\mathrm{BB}$ and $\mathrm{GN}$ designed the study and contributed equally to this work.

\section{Acknowledgements}

We thank Ms. Mahin Dorranipour for helping in graphic part.

\section{Competing interest}

The authors declare no competing interest.

\section{Availability of data and materials}

The datasets generated and/or analyzed during the current study are not publicly available due [because it is not general data] but are available from the corresponding author on reasonable request.

\section{Consent for publication}

Not applicable. 


\section{Ethics approval and consent to participate}

This study was approved and monitored by animal care center, Faculty of Veterinary Medicine, University of Tehran.

\section{Funding}

This work was supported by the University of Tehran under grant number 32/6/7502015 and colibacillosis vaccine design project.

\section{Publisher's Note}

Springer Nature remains neutral with regard to jurisdictional claims in published maps and institutional affiliations.

Received: 18 November 2017 Accepted: 11 May 2018

Published online: 16 May 2018

\section{References}

1. Rappuoli R. From Pasteur to genomics: progress and challenges in infectious diseases. Nat Med. 2004;10:1177-85.

2. Ünal CM, Schaar V, Riesbeck K: Bacterial outer membrane vesicles in disease and preventive medicine. In Seminars in immunopathology. Springer, New York; 2011: 395-408.

3. Lindmark B, Rompikuntal PK, Vaitkevicius K, Song T, Mizunoe Y, Uhlin BE, Guerry P, Wai SN. Outer membrane vesicle-mediated release of cytolethal distending toxin (CDT) from Campylobacter jejuni. BMC Microbiol. 2009;9:220.

4. Koeppen K, Hampton TH, Jarek M, Scharfe M, Gerber SA, Mielcarz DW, Demers EG, Dolben EL, Hammond JH, Hogan DA. A novel mechanism of host-pathogen interaction through sRNA in bacterial outer membrane vesicles. PLoS Pathog. 2016;12:e1005672.

5. Vanaja SK, Russo AJ, Behl B, Banerjee I, Yankova M, Deshmukh SD, Rathinam VA. Bacterial outer membrane vesicles mediate cytosolic localization of LPS and caspase-11 activation. Cell. 2016;165:1106-19.

6. Walker RI, Steele D, Aguado T. Committee AHETE: analysis of strategies to successfully vaccinate infants in developing countries against enterotoxigenic E. coli (ETEC) disease. Vaccine. 2007;25:2545-66

7. Lee C, Moseley S, Moon H, Whipp S, Gyles C, So M. Characterization of the gene encoding heat-stable toxin II and preliminary molecular epidemiological studies of enterotoxigenic Escherichia coli heat-stable toxin II producers. Infect Immun. 1983;42:264-8.

8. Levine MM. Escherichia coli that cause diarrhea: enterotoxigenic, enteropathogenic, enteroinvasive, enterohemorrhagic, and enteroadherent. Chicago: The University of Chicago Press; 1987

9. DuPont HL, Formal SB, Hornick RB, Snyder MJ, Libonati JP, Sheahan DG, LaBrec EH, Kalas JP. Pathogenesis of Escherichia coli diarrhea. N Engl J Med. 1971:285:1-9.

10. Nagy B, Fekete PZ. Enterotoxigenic Escherichia coli in veterinary medicine. Int J Med Microbiol. 2005:295:443-54.

11. Leitner DR, Lichtenegger S, Temel P, Zingl FG, Ratzberger D, Roier S, Schild-Prüfert K, Feichter S, Reidl J, Schild S. A combined vaccine approach against Vibrio cholerae and ETEC based on outer membrane vesicles. Front Microbiol. 2015:6:823.

12. Niewiesk S. Maternal antibodies: clinical significance, mechanism of interference with immune responses, and possible vaccination strategies. Front Immunol. 2014;5:446.

13. Boedeker EC. Vaccines for enterotoxigenic Escherichia coli: current status. Curr Opin Gastroenterol. 2005;21:15-9.

14. Moon HW, Bunn TO. Vaccines for preventing enterotoxigenic Escherichia coli infections in farm animals. Vaccine. 1993;11:213-20.

15. Roy K, Hamilton DJ, Munson GP, Fleckenstein JM. Outer membrane vesicles induce immune responses to virulence proteins and protect against colonization by enterotoxigenic Escherichia coli. Clin Vaccine Immunol. 2011:18:1803-8.

16. Kim OY, Hong BS, Park K-S, Yoon YJ, Choi SJ, Lee WH, Roh T-Y, Lötvall J, Kim Y-K, Gho YS. Immunization with Escherichia coli outer membrane vesicles protects bacteria-induced lethality via Th1 and Th17 cell responses. J Immunol. 2013;190:4092-102.
17. Roy K, Bartels S, Qadri F, Fleckenstein JM. Enterotoxigenic Escherichia coli elicits immune responses to multiple surface proteins. Infect Immun. 2010:78:3027-35

18. Park K-S, Choi K-H, Kim Y-S, Hong BS, Kim OY, Kim JH, Yoon CM, Koh G-Y, Kim Y-K, Gho YS. Outer membrane vesicles derived from Escherichia coli induce systemic inflammatory response syndrome. PLOS ONE. 2010;5:e11334.

19. Enioutina EY, Visic D, McGee ZA, Daynes RA. The induction of systemic and mucosal immune responses following the subcutaneous immunization of mature adult mice: characterization of the antibodies in mucosal secretions of animals immunized with antigen formulations containing a vitamin D3 adjuvant. Vaccine. 1999;17:3050-64.

20. Ahmed T, Bhuiyan TR, Zaman K, Qadri F: Vaccines for preventing enterotoxigenic Escherichia coli (ETEC) diarrhoea. The Cochrane Library 2011.

21. Deng G, Li W, Wu X, Bao S, Zeng J, Zhao N, Luo M, Liu X, Wang Y. Immunogenicity and protective efficacy of a recombinant adenoviral based vaccine expressing heat-stable enterotoxin (STa) and K99 adhesion antigen of enterotoxigenic Escherichia coli in mice. Mol Immunol. 2015;68:684-91.

22. Nataro JP, Kaper JB. Diarrheagenic Escherichia coli. Clin Microbiol Rev. 1998;11:142-201.

23. Croxen MA, Law RJ, Scholz R, Keeney KM, Wlodarska M, Finlay BB. Recent advances in understanding enteric pathogenic Escherichia coli. Clin Microbiol Rev. 2013;26:822-80.

24. Ivanov AP, Dragunsky EM, Chumakov KM. 1, 25-dihydroxyvitamin d3 enhances systemic and mucosal immune responses to inactivated poliovirus vaccine in mice. J Infect Dis. 2006;193:598-600.

25. Enioutina EY, Visic D, Daynes RA. The induction of systemic and mucosal immune responses to antigen-adjuvant compositions administered into the skin: alterations in the migratory properties of dendritic cells appears to be important for stimulating mucosal immunity. Vaccine. 2000;18:2753-67.

26. Guthrie T, Wong SY, Liang B, Hyland L, Hou S, Høiby EA, Andersen SR. Local and systemic antibody responses in mice immunized intranasally with native and detergent-extracted outer membrane vesicles from Neisseria meningitidis. Infect Immun. 2004;72:2528-37.

27. Beikzadeh B, Eftekhari Z, Erfanmanesh A. The isolating Escherichia coli secretory outer membrane vesicles by using tangential-trans flow filtration. Razi J Med Sci. 2017:24:8-14.

28. Greenfield EA. Antibodies: a laboratory manual. Cold Spring Harbor: Cold Spring Harbor Laboratory Press; 2013.

29. Harlow E, Lane D. A laboratory manual. New York: Cold Spring Harbor Laboratory; 1988. p. 579.

30. Duchet-Suchaux M: Infant mouse model of E. coli diarrhœa: clinical protection induced by vaccination of the mothers. In Annales de recherches vétérinaires. 1983: 319-331.

31. Schild S, Nelson EJ, Camilli A. Immunization with Vibrio cholerae outer membrane vesicles induces protective immunity in mice. Infect Immun. 2008;76:4554-63.

32. Franck SM, Bosworth BT, Moon HW. Multiplex PCR for enterotoxigenic, attaching and effacing, and Shiga toxin-producing Escherichia coli strains from calves. J Clin Microbiol. 1998;36(6):1795-7.

33. Al-Alo KZ, Nikbakht Brujeni G, Lotfollahzadeh S, Moosakhani F, Gharabaghi A. Correlation between neonatal calf diarrhea and the level of maternally derived antibodies. Iran J Vet Res. 2018;19(62):3-8.

34. Romani N, Flacher V, Tripp C, Sparber F, Ebner S, Stoitzner P: Targeting skin dendritic cells to improve intradermal vaccination. In Intradermal Immunization. Springer; 2011: 113-38.

35. Sparber F, Tripp CH, Hermann M, Romani N, Stoitzner P. Langerhans cells and dermal dendritic cells capture protein antigens in the skin possible targets for vaccination through the skin. Immunobiology. 2010;215:770-9.

36. Fehres CM, Garcia-Vallejo JJ, Unger WW, Van Kooyk Y. Skin-resident antigen-presenting cells: instruction manual for vaccine development. Front Immunol. 2013:4:157.

37. Pizzurro GA, Barrio MM. Dendritic cell-based vaccine efficacy: aiming for hot spots. Front Immunol. 2015;6:91.

38. Picot $\mathrm{V}$. Intradermal immunization: an alternative route for vaccine administration. Articles as per sessions meeting report. Vaccine. 2008;26:S1-5.

39. Kim S-H, Jang Y-S. The development of mucosal vaccines for both mucosal and systemic immune induction and the roles played by adjuvants. Clin Exp Vaccine Res. 2017:6:15-21. 
40. Srivastava A, Gowda DV, Madhunapantula SV, Shinde CG, lyer M. Mucosal vaccines: a paradigm shift in the development of mucosal adjuvants and delivery vehicles. APMIS. 2015;123:275-88.

41. Patel H, Yewale C, Rathi MN, Misra A: Mucosal immunization: a review of strategies and challenges. Critical Reviews ${ }^{\mathrm{TM}}$ in Therapeutic Drug Carrier Systems 2014, 31.

42. Kaul D, Ogra P. Mucosal responses to parenteral and mucosal vaccines. Dev Biol Stand. 1997;95:141-6.

43. Azegami T, Yuki Y, Kiyono $\mathrm{H}$. Challenges in mucosal vaccines for the control of infectious diseases. Int Immunol. 2014;26:517-28.

44. Ogra PL, Ogra SS. Local antibody response to poliovaccine in the human female genital tract. J Immunol. 1973;110:1307-11.

45. Smith DJ, Gahnberg L, Taubman MA, Ebersole JL. Salivary antibody responses to oral and parenteral vaccines in children. J Clin Immunol. 1986;6:43-9.
46. Tarkowski A, Lue C, Moldoveanu Z, Kiyono H, McGhee J, Mestecky J. Immunization of humans with polysaccharide vaccines induces systemic predominantly polymeric IgA2-subclass antibody responses. J Immunol. 1990;144:3770-8.

47. Bouvet J-P, Decroix N, Pamonsinlapatham P. Stimulation of local antibody production: parenteral or mucosal vaccination? Trends Immunol. 2002;23:209-13.

48. Glenn GM, Scharton-Kersten T, Vassell R, Mallett CP, Hale TL, Alving CR. Cutting edge: transcutaneous immunization with cholera toxin protects mice against lethal mucosal toxin challenge. J Immunol. 1998;161:3211-4.
Ready to submit your research? Choose BMC and benefit from:

- fast, convenient online submission

- thorough peer review by experienced researchers in your field

- rapid publication on acceptance

- support for research data, including large and complex data types

- gold Open Access which fosters wider collaboration and increased citations

- maximum visibility for your research: over $100 \mathrm{M}$ website views per year

At BMC, research is always in progress.

Learn more biomedcentral.com/submissions 